\title{
High-definition analysis of fluid-induced seismicity related to the mesoscale hydromechanical properties of a fault zone
}

\author{
Yves Guglielmi, ${ }^{1}$ Frédéric Cappa,${ }^{1}$ and David Amitrano ${ }^{2}$ \\ Received 21 December 2007; revised 31 January 2008; accepted 12 February 2008; published 22 March 2008.
}

[1] Interactions between pore pressure, strain and seismicity were analyzed in a 30-m-thick shallow fault zone that was subjected to a small overpressure of $80 \mathrm{kPa}$ to produce small changes in effective stress. Simultaneous pressure-strain and seismic measurements taken in the fractured damage zone during the pressurization indicated that seismicity is triggered along low-permeable, highly rigid, low-dip angle, mesoscale-inherited fractures where deformation is controlled by the hydromechanical behavior of the surrounding high-permeability, not-so-rigid, aseismic, subvertical, fault-related fractures. Using a three-dimensional distinct-element representation of the fractures network, we show that the seismicity observed is mainly due to shearslip along inherited planes in response to the mechanical loading induced by the opening by a few microns of the surrounding subfaults. Citation: Guglielmi, Y., F. Cappa, and D. Amitrano (2008), High-definition analysis of fluidinduced seismicity related to the mesoscale hydromechanical properties of a fault zone, Geophys. Res. Lett., 35, L06306, doi:10.1029/2007GL033087.

\section{Introduction}

[2] Fluid and fracture interactions in the Earth's crust are of great importance for seismic processes [Berryman, 2007]. Fractures, which are probably the most common brittle and flow-conducting structures in the crust, have been intensively investigated near active fault zones [Faulkner et al., 2006]. Seismic events induced by a change in pore pressure conditions in the crust are now well documented, particularly in cases of reservoir-induced seismicity [Talwani, 1997], the injection or pumping of fluids in sub-surface wells [Zoback and Harjes, 1997], and pore-pressure-driven aftershocks in the seismogenic crust [Miller et al., 2004]. Seismicity in rocks with fractures and fluids can be attributed both to an undrained response to loading and to a delayed coupled poro-mechanical response, where pore pressure diffusion is one of the predominant causes [Rajendran and Talwani, 1992].

[3] Data collected during fluid-induced seismicity are of great interest towards our better understanding of the seismogenic crust, and in particular, to estimate changes in stress, hydraulic diffusivity and strength near active fault zones, which are particularly important parameters for seismic processes. Many efforts have been made to understand the links between pore pressure and seismicity, particularly in the case of fluid-injection-induced seismicity

\footnotetext{
${ }^{1}$ Géosciences Azur, University de Nice Sophia-Antipolis, Nice, France.

${ }^{2}$ LGIT, Universite Joseph Fourier, Grenoble, France.
}

Copyright 2008 by the American Geophysical Union. 0094-8276/08/2007GL033087
[Cornet et al., 1997; Shapiro et al., 1999]. These studies have shown that the dynamics of microseismic clouds generally reflect zones where pore pressure has increased, and zones where hydromechanical effects occur both along large-scale fractures and in the intact rock. In addition, Parotidis et al. [2005] suggested that seismicity is generally localized in the highly fractured, highly diffusive patches of fault zones. However, most of these studies have analyzed the physical processes in a large rock volume with a spatial characteristic size of the order of $1 \mathrm{~km}$, where the hydromechanical effects at the scale of a so-called "fractured patch" in the work by Parotidis et al. [2005] remaining difficult to characterize, both by seismic wave measurements and by borehole studies.

[4] In the present study, we have analysed in situ the interactions between seismicity, strain and pore pressure inside the "fractured patch" of the exhumed portion of a shallow fault zone in a carbonate rock that is particularly well exposed at the Coaraze Laboratory in France [Cappa et al., 2007]. Our goal was to examine with high-resolution the fluid-mechanical couplings inside a fractured patch with a high permeability and low stiffness on the global scale, and where earthquakes are located when the fault zone is studied at larger scales, as in the work by Parotidis et al. [2005]. Fluid-induced seismicity was thus investigated at the mesoscopic-scale, an intermediate scale between the laboratory and the reservoir. To our knowledge, these simultaneous measurements of changes in pore pressure, strain and seismicity along several fractures and in the intact rock during a fluid injection represent new data in the field. Here, the fluid injection produced small changes in effective stress (tens of $\mathrm{kPa}$ ) compared to those produced in conventional large-scale fluid-injection-induced seismicity experiments (a few MPa).

[5] The studied fault zone of the Coaraze research site corresponds to a subvertical, 30-m-thick dextral strike-slip fault, which is located $20 \mathrm{~km}$ east of Nice, at the junction between the Southern Alps and the Ligurian Basin, a moderately active seismic area for Western Europe (Figure 1a). Some segments of the fault show earthquake seismic activity at magnitudes of up to 6.0 , and at depths of $2 \mathrm{~km}$ to $6 \mathrm{~km}$. The fault zone structure was presented in detail by Cappa et al. [2007], with a deep description of the core, damage zone and protolith architecture. Schematically, it is a complex fault zone with a 5-m-wide core made up of fine grained breccia and surrounded by a damage zone that is several meters thick. In this damage zone, there are two sets of subvertical faultrelated fractures (subfaults) and one family of inherited bedding planes, both of which have lengths of tens of meters (Figures $1 \mathrm{~b}$ and 1c). At Coaraze, the exhumed portion of this fault zone is a mesoscale fractured carbonate reservoir $(30 \mathrm{~m} \times 30 \mathrm{~m} \times 15 \mathrm{~m})$ with an unconfined aquifer 

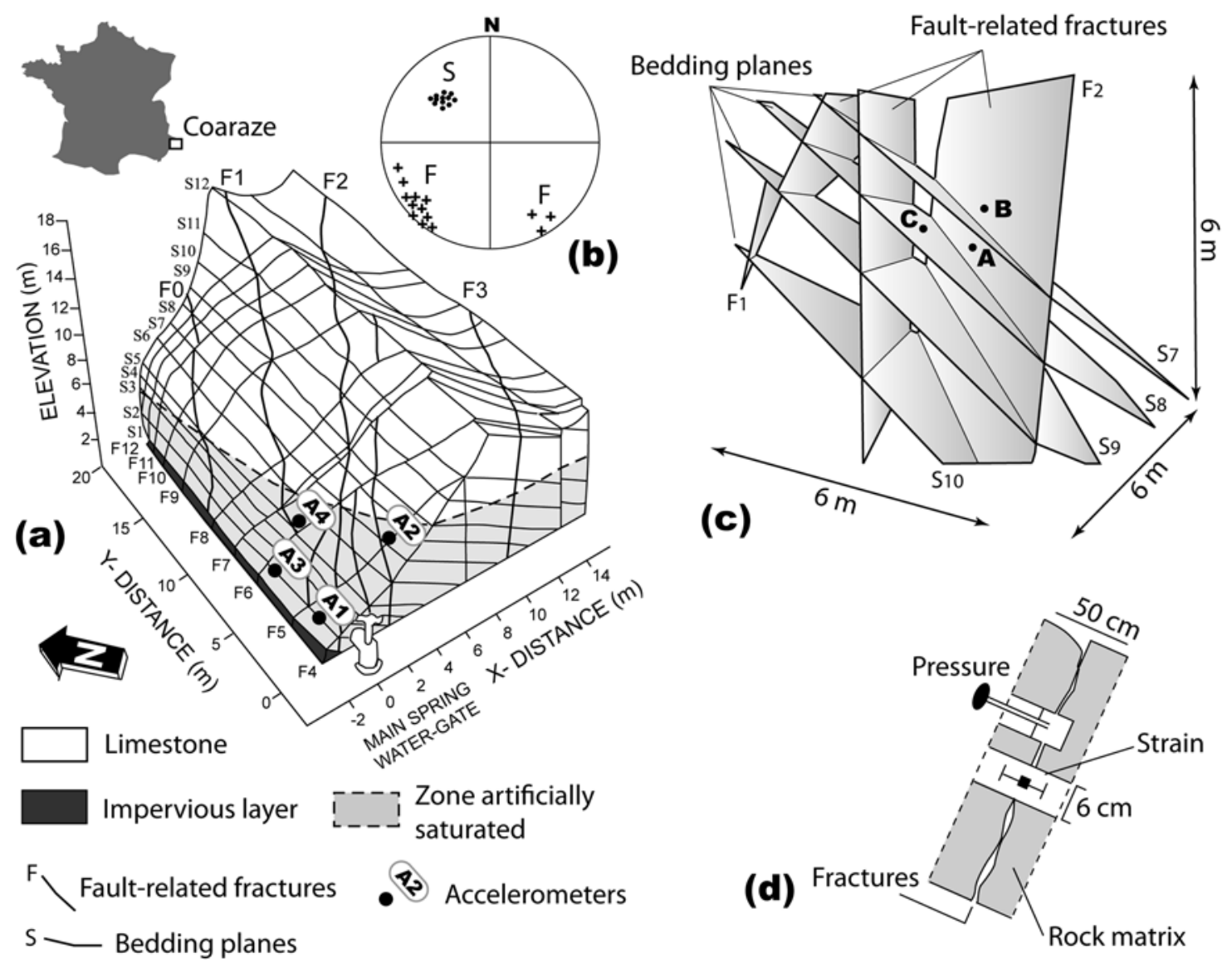

Figure 1. (a) Three-dimensional view of the fault zone structure with the instrumental devices; (b) Pole plots showing the subfaults and bedding-plane orientations (lower hemisphere); (c) Three-dimensional distinct element representation of the fracture network in the damage zone; (d) Pressure and strain sensors, and experimental device set in the fault zone.

drained by a natural spring (Figure 1a). For our purposes, the spring was closed to allow an artificial moderate pressurization of the fault zone (by opening or closing the gate). Moreover, reservoir mesoscale fractures and intact rock were extensively instrumented for fully coupled hydraulic and mechanical measurements during pressure changes. Within the framework of this study, we added seismic sensors set on the topographic surface of the fault damage zone. In this study, we have interpreted the data obtained, giving special attention to the interactions between hydromechanical effects and seismicity induced during a low-pressure increase (by closing the gate) in the fault damage zone. Then, we have conducted a numerical analysis to investigate how the shearing process that is responsible for the observed seismicity can initiate and propagate in the fracture network within the damage zone in response to a low-pressure pulse. Through our investigations, we have shown that the seismicity of the fault zone is mainly induced along the low-permeability, highly rigid inherited fractures, where local shear-slips take place during the pressure buildup, whereas the subfaults are aseismic due to their highpermeability and low-rigidity.

\section{Seismic and Hydromechanical Instrumental Set-Up in the Fault Damage Zone}

[6] Inside the fault damage zone, changes in pore pressure and strain were simultaneously monitored at single discontinuities and in the intact rock, using short-base extensometers and pressure gauges. At several so-called coupled pressure-strain points, two sensors were installed (by two small borings, Figure 1d), so as not to disturb the state-of-stress inside the reservoir. Pore pressure measurements were carried out using a vibrating-wire interstitial pressure sensor with an accuracy of $0.5 \mathrm{kPa}$. Strain measurements were conducted using a 0.15-m-long 'RocTest-Telemac' vibrating-wire extensometer, with an accuracy of $0.5 \times 10^{-6} \mathrm{~m} / \mathrm{m}$.

[7] Within the framework of this study, four monodirectional accelerometers (A1 to A4), and Wilcoxon sensor models (Model 793L, which has a flat response in the range of 1 to $300 \mathrm{~Hz}$, with $500 \mathrm{mV} / \mathrm{g}$ sensitivity) were placed near the topographic surface, in small boreholes drilled at a depth ranging from $0.4 \mathrm{~m}$ to $0.6 \mathrm{~m}$, depending on the points (A1 to A4 in Figure 1a).

[8] Pressure-strain measurements were simultaneously registered with a 1-min sampling-rate interval, using a Campbell CR10X data station. The accelerometers were connected to an analogical-digital converter with 16-bit resolution, a $20 \mathrm{kHz}$ sampling rate, and a 0.1 to $2300 \mathrm{~Hz}$ bandwidth on $-3 \mathrm{~dB}$. These stations were located very close to the sensors (a few meters from them) and wrapped in thermo-isolating materials, so that temperature effects on the connecting cables were negligible. The experiments were short $(15 \mathrm{~min})$ to assure that temperature variations 


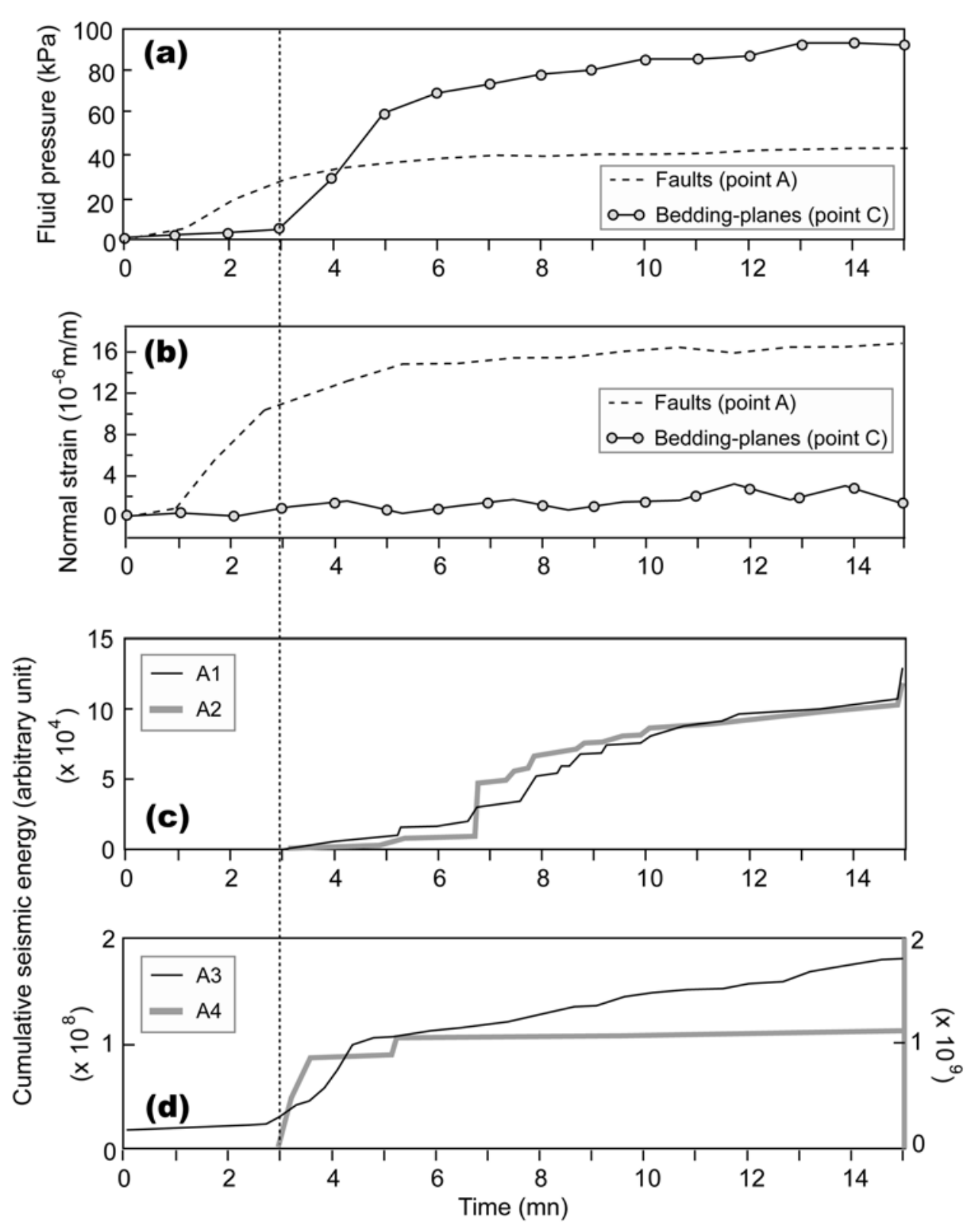

Figure 2. Changes in (a) fluid pressure, (b) fracture-normal-mechanical-strain, and cumulative seismic energy at (c) A1 - A2 and (d) A3-A4, measured by all of the sensors during the $15 \mathrm{~min}$ of hydraulic loading. See Figure 1c for locations of measuring points. CSE recorded at A3-A4 is four orders of magnitude larger than the one at A1-A2. This is due both to the attenuation and the distance between the sources and the sensors.

would have minimal effects on the measurements. Both acquisition stations were synchronized.

\section{Fault-Zone Seismic and Hydromechanical Responses: Experimental Results}

[9] The initial conditions corresponded to an opened water gate, so that the fault zone was fully unsaturated. The water gate was then closed for a 15-min period to induce a free water-surface build-up of about $80 \mathrm{kPa}$ near the gate.

[10] When the water gate was closed, contrasting hydromechanical behaviors were seen. In subfaults, the pressure increased to $35 \mathrm{kPa}$ in less than $4 \mathrm{~min}$, and reached $40 \mathrm{kPa}$ at the end of the loading, with an associated normal opening of subfaults measured (Figures $2 \mathrm{a}$ and $2 \mathrm{~b}$ ). The deformation magnitude was $16 \times 10^{-6} \mathrm{~m} / \mathrm{m}$. In bedding planes, the pressure increase was slower than in vertical subfaults (Figure 2a), and it took $4 \mathrm{~min}$ to $15 \mathrm{~min}$ to increase to $90 \mathrm{kPa}$. Moreover, no significant normal deformation was measured. In addition, 10 pulse tests were conducted with the high-pulse poroelasticity protocol (HPPP) to estimate the local poroelastic properties of fractures (details of the HPPP can be found in the work by Cappa et al. [2006] and Y. Guglielmi et al., A new approach for in situ characterization of rock slope discontinuities: The "High-Pulse Poroelasticity Protocol" (HPPP), paper to be presented at the 10th International Symposium on Landslides and Engineered Slopes (2008)). Our results here show that fluid flow and deformations in the fault zone are controlled by the 

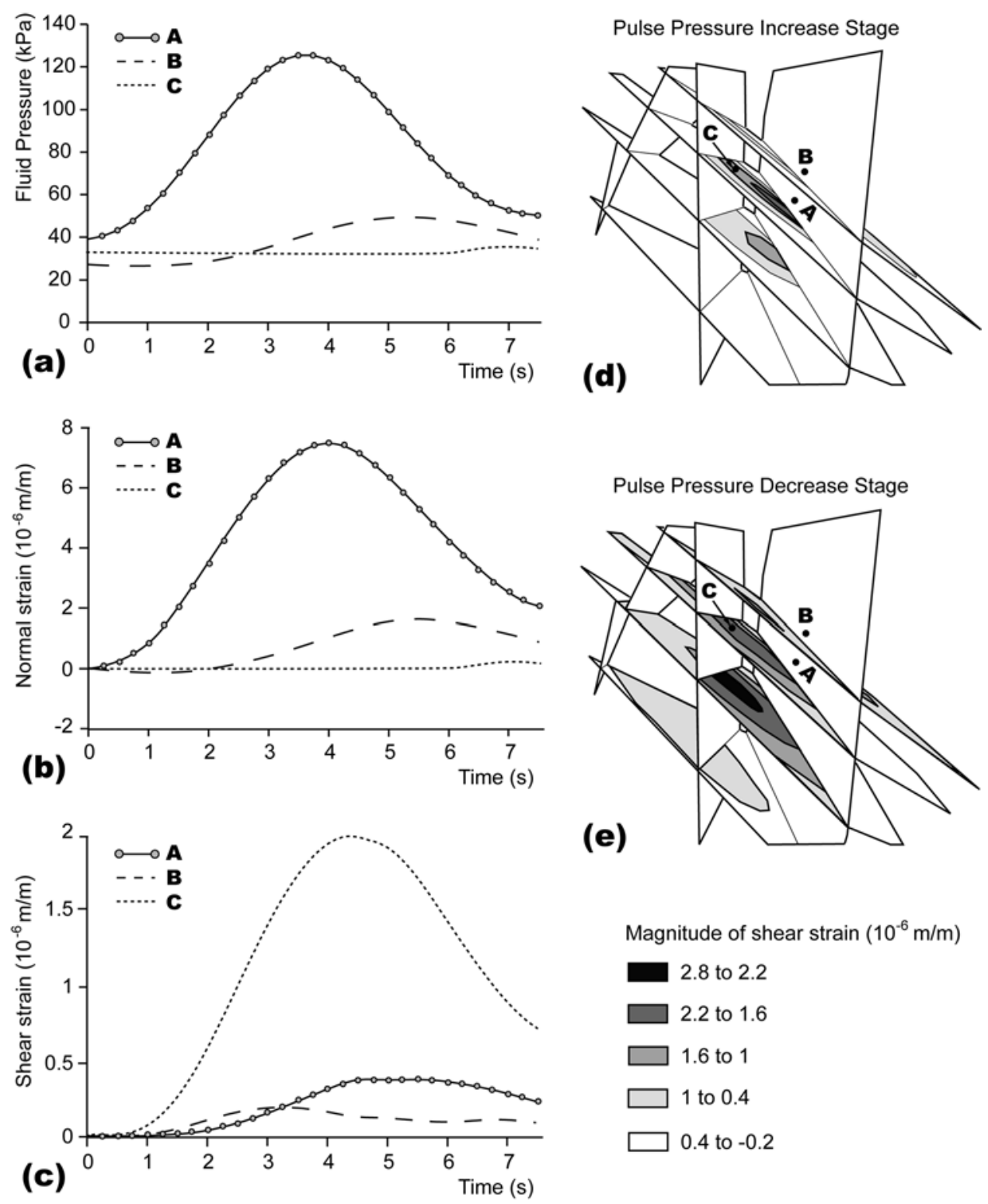

Figure 3. Hydromechanical responses to the pressure pulse, with changes in: (a) fluid pressure, (b) normal strain, (c) shear strain; and zones of shearing during (d) the pulse pressure increase stage, and (e) the pulse pressure decreasing stage.

strong contrast of poroelastic properties, with highly permeable, low-stiff subfaults $\left(\mathrm{k}=10^{-12} \mathrm{~m}^{2}, \mathrm{k}_{\mathrm{n}} \sim 15 \mathrm{GPa} / \mathrm{m}\right)$ bounding low-permeable, highly rigid, bedding planes $\left(\mathrm{k}=10^{-14} \mathrm{~m}^{2}, \mathrm{k}_{\mathrm{n}} \sim 100 \mathrm{GPa} / \mathrm{m}\right)$.

[11] When the pressure was increased in the subfaults, no seismic activity was seen. Pressure increase effects in bedding planes were clearly seen on all of the accelerometers, where significant increases in cumulative seismic energy (CSE) were recorded (Figures 2c and 2d). CSE magnitudes of $1.1 \times 10^{5}$ to $1.1 \times 10^{9}$ were measured. Due to the high attenuation and low signal energy, seismic events were never seen simultaneously on the four accelerometers, preventing any location of the events. Nevertheless, this demonstrates that events are localized at the infra-metric to metric scale (lower than the seismic network scale). Time variations of the CSE, which are quite complex, can be schematically described by a fast initial variation in A3 and A4, within the first 30-sec period of pressure build-up in bedding planes, followed by a slow variation over $4.50 \mathrm{~min}$ to $15 \mathrm{~min}$. In $\mathrm{A} 1$ and $\mathrm{A} 2$, the variation in CSE also correlated with pressure increases in bedding planes. The CSE increase was lower and slower than in A3 and A4, and it took $3 \mathrm{~min}$ to $6.50 \mathrm{~min}$ to increase significantly, followed by slow variations until the end of the hydraulic loading. The delay in the seismic response between sensors $\mathrm{A} 1-\mathrm{A} 2$ and $\mathrm{A} 3-\mathrm{A} 4$ corresponds to the different locations of the sensors relative to the main fractures.

\section{Numerical Analysis of Shearing Initiation in the Fractures Network Within the Fault Damage Zone}

\subsection{Modelling Set-Up}

[12] To investigate fluid-strain coupling on initiation of shear-slip in the fractures network within the fault damage 
Table 1. Model Parameters Inferred From the In Situ and Laboratory Tests ${ }^{\mathrm{a}}$

\begin{tabular}{lccc}
\hline \multicolumn{1}{c}{ Model Parameters ${ }^{\mathrm{b}}$} & Subfaults & Bedding Planes & Rock Matrix \\
\hline Young's modulus, $E_{R}, \mathrm{GPa}$ & - & - & 70 \\
Poisson's ratio, $\nu_{R}$ & - & - & 0.29 \\
Mass density, $\rho_{R}, \mathrm{~kg} / \mathrm{m}^{3}$ & - & - & 2400 \\
Normal stiffness, $k_{n}, \mathrm{GPa} / \mathrm{m}$ & $17(\mathrm{~A}), 50(\mathrm{~B})$ & 100 & - \\
Shear stiffness, $k_{s}, \mathrm{GPa} / \mathrm{m}$ & $1.7(\mathrm{~A}), 5(\mathrm{~B})$ & 10 & - \\
Roughness factor, $f$ & 1 & 1 & - \\
Cohesion, $c, \mathrm{kPa}$ & 10 & 10 & - \\
Friction coefficient, $\mu_{s}$ & 0.6 & $1 \times 10^{-5}$ & - \\
Initial hydraulic aperture, $b_{h i}, \mathrm{~m}$ & $1 \times 10^{-4}(\mathrm{~A})$ & & - \\
\end{tabular}

${ }^{\mathrm{a}}$ See Cappa et al. [2006] for more details.

${ }^{\mathrm{b}}$ Parameters with index (A) and (B) have been affected to points A and B along the pressurized subfault $\mathrm{F}_{2}$.

zone, we developed a three dimensional (3D) distinctelement hydromechanical model, which assumed the same rigidity-permeability contrast as that measured in the field. The goal of the numerical model presented here was to simulate the general hydromechanical effects, as seen by the data analysis in section 3. For that, the 3DEC code [Cundall, 1988] was used to analyze shearing processes due to an overpressure of $80 \mathrm{kPa}$ applied at point $\mathrm{A}$ in a highpermeability sub-fault during the short period of $7.5 \mathrm{sec}$ (Figure 3a). This model allowed a detailed evaluation of the shearing effects to fluid-strain coupling.

[13] The code simulates the fluid-flow and deformationcoupled processes of discrete fractures embedded in an impervious rock matrix. A modified form of the cubic law (1) governs fluid flow in fractures [Witherspoon et al., 1980]:

$$
q=\frac{\left(b_{h i}+f \Delta U_{n}\right)^{3} w \rho g}{12 \mu} \Delta h
$$

where $q$ is the flow rate, $b_{h i}$ is the initial hydraulic aperture at the initial effective stress, $f$ is a factor reflecting the influence of the roughness on the tortuosity of the flow, $\Delta U_{n}$ is the change in fracture normal displacement, $w$ is the fracture width, $\rho$ is the fluid density, $g$ is the gravitational acceleration, $\mu$ is the fluid dynamic viscosity, and $\Delta h$ is the change in hydraulic head. Fracture deformations and hydraulic apertures are calculated as a function of the effective stresses, assuming a constant normal stiffness for fractures which can be reasonably admitted due to the infinitesimal strains measured in the experiment. In the numerical analyses conducted here, the rock matrix behaves as an elastic material, whereas discontinuities are considered to be elasto-plastic and thus can reach an inelastic slip state when the shear stress acting in the plane exceeds its shear strength, approximated by a Coulomb criterion:

$$
\tau=c+\mu_{s}\left(\sigma_{\mathrm{n}}-P\right)
$$

where $\tau$ is the critical shear stress for failure occurrence, $c$ is the cohesion, $\mu_{s}$ is the static friction coefficient, $\sigma_{n}$ is the normal stress, and $P$ is fluid pressure.

[14] The model corresponds to an explicit 3D representation of the fracture network in a small portion $(6 \mathrm{~m} \times 6 \mathrm{~m} \times$ $6 \mathrm{~m}$ ) of the fault damage zone (Figure 1c). A discrete model was analyzed, taking into account seven mesoscale fractures: three subfaults $\left(\mathrm{F}_{1-2}\right)$ and four bedding planes $\left(\mathrm{S}_{7-10}\right)$.
In-situ and boundary fluid pressures were set according to the natural hydrostatic pressure gradient in the rock mass. On the top boundary, a vertical stress corresponding to the weight of the overburden rock mass was applied, with displacements fixed to zero at other boundaries.

[15] The mechanical properties of the rock matrix and the hydromechanical properties of the subfaults and bedding planes (Table 1) were taken from previous in-situ and laboratory experiments [Cappa et al., 2006]. For each simulation, the pressure pulse was simulated by imposing a time-dependent pressure pulse at the point source, A (Figure 3a). The computation is in the low-frequency domain, with fluid and solid motion in phase. The pore pressure and the normal and shear strains were simultaneously controlled at points A, B and C, respectively, in the subfault and in the bedding plane (Figure 1c).

\subsection{Modelling Results}

[16] The model results indicate that the overpressure caused by the injection produce a pressure gradient that was mainly distributed in the pressurized subfault (Figure 3a). Nevertheless, part of the fluid flow occurs within the bedding plane portions $\left(\mathrm{S}_{7}\right.$ and $\left.\mathrm{S}_{8}\right)$ very close to points $\mathrm{A}$ and $\mathrm{B}$, whereas the pore pressure slightly increases at point $\mathrm{C}$ at the end of the injection. During the pulse-pressure increase, the subfault opens with a higher magnitude in $\mathrm{A}\left(\Delta \varepsilon_{\mathrm{n}}=7.5 \times\right.$ $\left.10^{-6} \mathrm{~m} / \mathrm{m}\right)$ than in $B\left(\Delta \varepsilon_{\mathrm{n}}=2 \times 10^{-6} \mathrm{~m} / \mathrm{m}\right)$, whereas fluid flow within the bedding planes does not induce a mechanical opening along these planes (Figure $3 b$ ). In addition, the fault opening causes zones of inelastic shear-slip along bedding planes that show a magnitude (max. $\Delta \varepsilon_{\mathrm{s}}$ at point $\mathrm{C}=2 \times 10^{-6} \mathrm{~m} / \mathrm{m}$ ) that is of the same order as the normal strain at point B (Figures $3 \mathrm{c}$ and $3 \mathrm{~d}$ ). The shear strain along the subfault remains elastic, with magnitudes largely lower by a factor from $\sim 5$ to 10 than in the bedding planes $\left(\Delta \varepsilon_{\mathrm{s}}=0.2 \times 10^{-6} \mathrm{~m} / \mathrm{m}\right.$ in $A$, and $\Delta \varepsilon_{\mathrm{s}}=0.36 \times 10^{-6} \mathrm{~m} / \mathrm{m}$ in B), where most of the shear-slips are concentrated (Figure 3d). During pressure-pulse decreases at the injection point, progressive bedding plane shearing still occurs far from the pressurized subfault, and propagates with higher magnitudes $\left(\max . \Delta \varepsilon_{\mathrm{s}}=2.8 \times 10^{-6}\right.$ $\mathrm{m} / \mathrm{m}$ ) in a larger portion of the bedding-plane network than in the pulse-pressure increase stage (Figure 3e). This is caused by the propagation of the pressure wave within the bedding planes. Indeed, the pressure increases with small magnitudes away from the injection point, with a certain time delay, and induces lowered effective stress within 
weakened bedding planes (Figure $3 \mathrm{a}$, at $\mathrm{t}=6.25 \mathrm{~s}$ ). This induces delayed mechanical strain (Figures $3 b$ and $3 c$ ).

\section{Discussion and Conclusions}

[17] Our in-situ investigations at Coaraze indicate the central role of coupled hydromechanical effects on seismicity induced in the mesoscale fractures network of a shallow fault zone, during low-magnitude overpressure. Indeed, measurements reveal that even for low pore pressure changes, hydromechanical effects in the fractured damage zone can produce observable seismicity. Strong, but very different, coupling between pore pressure, normal strain and seismic energy has been identified when interpreting field data. The fractures network behaves like a doubleporosity, highly deformable fractured media, with connected, highly permeable, not-so-rigid, aseismic subfaults, and lowpermeability, low-rigidity, seismic bedding planes. This finding is in agreement with the study of Matthäi and Belayneh [2004], which showed that the partitioning of fluid pressure between fractures and rock matrix reveal critical aperture values that mark the transition from matrixdominated to fracture-dominated flow.

[18] Seismic activity measured along bedding planes does not correlate to normal strains, but is explained by inelastic shear-slips. Through numerical simulations, shear-slip along these seismogenic planes is interpreted as initiated by poroelastic strain transfer from the elastically deformed subfaults to bedding planes optimally oriented to slip under effective stress regime. This means that mechanical deformation in these seismogenic planes is controlled by the opening by a few microns of surrounding subfaults.

[19] Our study thus suggests that the generation and maintenance of fluid pressure (even at low pressure levels) and the associated hydromechanical effects and the mesoscale hydromechanical properties within the fracture patches of fault zones are of particular importance in crustal processes, as they have a major role in both the aseismic and seismic slip events. At the kilometric-scale, Parotidis et al. [2005] clearly showed that seismicity is mainly localized in the fractured patches of fault zones. Thus, our detailed analysis at the scale of a so-called "fractured patch" provides new insights into the origins of seismic events due to small pressure build-up. Moreover, our results show how in-situ measurement of both normal and shear strains of fractures is important to improve our knowledge of seismic processes in fault zones through the seismogenic crust. It shows that the induced seismicity is instead located in low-permeable, high-stiff zones and indirectly induced by poroelastic strains in high-permeable and low-stiff zones.
Seismicity can then be linked to localized micro-slips along pre-existing fractures under a critical stress state and with a low strength.

[20] Acknowledgments. We are grateful for the constructive comments of the anonymous reviewers, who helped us to substantially improve our manuscript. DA is supported by the ANR INSU-CATELL French government program (ref: ANR-06-CATT-011). YG and FC acknowledge the French government for the financial support of the project ANR HPPPCO2 (ref: ANR-07-PC02-002).

\section{References}

Berryman, J. G. (2007), Seismic waves in rocks with fluids and fractures, Geophys. J. Int., 171, 954-974, doi:10.1111/j.1365-246X. 2007.03563.X.

Cappa, F., Y. Guglielmi, J. Rutqvist, C.-F. Tsang, and A. Thoraval (2006), Hydromechanical modeling of pulse tests that measure fluid pressure and fracture normal displacement at the Coaraze Laboratory site, France, Int. J. Rock Mech. Min. Sci., 43, 1062-1082.

Cappa, F., Y. Guglielmi, and J. Virieux (2007), Stress and fluid transfer in a fault zone due to overpressures in the seismogenic crust, Geophys. Res. Lett., 34, L05301, doi:10.1029/2006GL028980.

Cornet, F. H., J. Helm, H. Pointrenaud, and A. Etchecopar (1997), Aseismic and seismic slips induced by large-scale fluid injections, Pure Appl. Geophys., 150, 863-883.

Cundall, P. A. (1988), Formulation of a three-dimensional distinct element model-part I. A scheme to detect and represent contacts in a system composed of many polyhedral blocks, Int. J. Rock Mech. Min. Sci. Geomech. Abstr., 25, 107-116.

Faulkner, D. R., T. M. Mitchell, D. Healy, and M. J. Heap (2006), Slip on 'weak' faults by the rotation of regional stress in the fractured damage zone, Nature, 444, 922-925, doi:10.1038/nature05353.

Matthäi, S. K., and M. Belayneh (2004), Fluid flow partitioning between fractures and a permeable rock matrix, Geophys. Res. Lett., 31, L07602, doi:10.1029/2003GL019027.

Miller, S. A., C. Collettini, L. Chiaraluce, M. Cocco, M. Barchi, and B. J. P. Kaus (2004), Aftershocks driven by a high-pressure $\mathrm{CO}_{2}$ source at depth, Nature, 427, 724-727.

Parotidis, M., S. A. Shapiro, and E. Rothert (2005), Evidence for triggering of the Vogtland swarms 2000 by pore pressure diffusion, J. Geophys. Res., 110, B05S10, doi:10.1029/2004JB003267.

Rajendran, K., and P. Talwani (1992), The role of elastic, undrained, and drained responses in triggering earthquakes at Monticello reservoir, South Carolina, Bull. Seismol. Soc. Am., 82(4), 1867-1888.

Shapiro, S. A., P. Audigane, and J. J. Royer (1999), Large-scale in-situ permeability tensor of rocks from induced seismicity, Geophys. J. Int., 137, 207-213.

Talwani, P. (1997), On the nature of reservoir-induced seismicity, Pure Appl. Geophys., 150, 473-492.

Witherspoon, P. A., J. S. Y. Wang, K. Iwai, and J. E. Gale (1980), Validity of cubic law for fluid flow in a deformable rock fracture, Water Resour. Res., 16, 1016-1024.

Zoback, M. D., and H.-P. Harjes (1997), Injection-induced earthquakes and crustal stress at $9 \mathrm{~km}$ depth at the KTB deep drilling site, Germany, J. Geophys. Res., 102, 18,477-18,491.

D. Amitrano, LGIT, Universite Joseph Fourier, BP 53, Grenoble F-38041, France. (amitrano@ujf-grenoble.fr)

F. Cappa and Y. Guglielmi, Géosciences Azur, University of Nice Sophia-Antipolis, 250, rue A. Einstein, Sophia Antipolis, F-06560 France. (cappa@geoazur.unice.fr, guglielmi@geoazur.unice.fr) 